\title{
An insight on the greenhouse gas emission from the metals process industries and its effects on climate change
}

\begin{abstract}
This article presents the research outcomes published in various scientific journals on problems and solutions of carbon emission from metals process industries. This paper has focused on potential metals process industries, which are associated with economic development and as well as are responsible for a significant amount of carbon emission. To achieve the goals of the study, the methodology has developed for collecting required information from the relevant journals published in the years 1990 to 2019 for supporting to the ongoing global activities in achieving sustainable development and to mitigate climate change effects. The study revealed that the Steel, Aluminium, Copper, Zinc, and Magnesium process industries are the potential Greenhouse Gas emission sources including Carbondioxide, Methane, and Nitrogen dioxide gases. The reported carbon concentration in the Atmosphere was 242ppm in 2018, 404ppm in 2017, 365.48ppm in 2000 and $354.19 \mathrm{ppm}$ in 1990. However, if this trend continues, the carbon concentration in the air would be $465 \mathrm{ppm}$ in 2050 and about $700 \mathrm{ppm}$ in 2100, which may increase further earth surface temperature from $3.7^{\circ} \mathrm{C}$ to $7.8^{\circ} \mathrm{C}$. At the global level, the estimated carbon emission from manufacturing industries was about 42 percent which was accounted for $21.5 \mathrm{Gt}$ in 2018 , $19.32 \mathrm{Gt}$ in $2017,13.8 \mathrm{Gt}$ in 2015 , and $10.5 \mathrm{Gt}$ in 2000 .It was reported that the relevant stakeholders made required strategies to keep temperature increase well below $2^{\circ} \mathrm{C}$ with respect to the Pre-industrial level by reducing carbon emission; and in that aspect, the metals processing industries could play a vital role. This study also revealed that nowadays, a few technologies are available and these would be the part of metals processing industries to reduce carbon emission. This study found that the metals process industries indeed are a potential part of the global carbon emission, and contributing to increasing global warming and climate change. The study concludes that this article indeed would be a potential reference for future researches in this the field in developing models for reducing carbon emission from metal process industries toward mitigating climate change effects.
\end{abstract}

Volume 3 Issue 6 - 2019

\author{
Shahidul Islam M \\ Department of Mechanical and Manufacturing Engineering, \\ Universiti Malaysia Sarawak, Malaysia
}

Correspondence: Shahidul Islam, Faculty of Engineering,
Department of Mechanical and Manufacturing Engineering,
Universiti Malaysia Sarawak, 94300 Kota Samarahan, Sarawak, Malaysia,Email mislam@unimas.my

Received: October 18,2019 | Published: November 13, 2019

Keywords: climate change, engineering contribution, metals process, carbon capture, carbon emission

Abbreviations: GHG, Greenhouse Gas; GWP, global warming potentials; F-gases, Fluorinated gases

\section{Introduction}

The metals process the industry is a source of Greenhouse Gas (GHG), and the major components of these gases are $\mathrm{CO}_{2}, \mathrm{CH}_{4}$, $\mathrm{N}_{2} \mathrm{O}$ and Fluorinated gases (F-gases). The GHG is responsible for global warming potentials (GWP) and climate change. ${ }^{1,2}$ However, the common source of GHG emission is electricity production from fossil fuel to operate metals industries and as well from metals processing. ${ }^{3}$ The carbon dioxide in the atmosphere is about 65 percent. ${ }^{4}$ The methane is the second-largest carbon in GHG after $\mathrm{CO}_{2}$, which accounted for 16 percent of global emission. The effect of $\mathrm{CH}_{4}$ on GWP and climate change is about 25 percent higher than $\mathrm{CO}_{2}{ }^{5,6}$ Nitrous oxide is also a part of GHG in the atmosphere, and its contribution to GHG is about 6 percent. It has been reported that the metal process industries are a major emission source of $\mathrm{N}_{2} \mathrm{O} .{ }^{7,8}$ The Fluorinated gas is a part of GHG and has a significant effect on climate change. The fact is the process of the metal industries are associated with Fluorinated gas emission. This gas includes hydrofluorocarbons (HFCs), perfluorocarbons (PFCs), and sulfur hexafluoride SF6. ${ }^{9,10}$ The Magnesium (Mg), Zinc, Lead, and other metals processing industries are the emitter of this gas. ${ }^{11}$ However, in a report, IEA stated that the burning of fossil fuel for electricity production to operate heavy industries like Iron, and Aluminum, Zinc. Magnesium and copper and significantly responsible for GWP.,12

\section{Operations of metals process industries and problem in managing enviromental pollutions}

The metals process industries are responsible for a significant amount of carbon emission. The Steel, Aluminium, Copper, Zinc, and Magnesium process industries are the emitting sources of Carbondioxide, Methane, and Nitrogen dioxide gases. The reported carbon concentration in the atmosphere was $242 \mathrm{ppm}$ in $2018,404 \mathrm{ppm}$ in 2017, 365.48ppm in 2000 and 354.19ppm in 1990; and the metals process industries, indeed, a contributor to that carbon concentration. It indicates that a problem exists in operations of metals process industries in controlling GHG emission, and the required efforts are not putting in place to solve it. The strategic goal of this paper is to list the emission level of the major metals process industries with relevant sustainable solutions.

\section{Objective}

The broad objective of this paper is to present information that 
gathered from journals published on research findings in carbon emission from the process of the major metal industries; and its sustainable solutions for reducing carbon concentration in the atmosphere.

\section{Novelty of the work}

The novelty of this research is to present problems and sustainable solutions concisely of carbon emission from metals process industries to be used by the researchers and policymakers.

\section{Materials and methods}

To collect information on carbon emission from the metals process industries, literature review has conducted. To achieve the goals of the study, the methodology has developed for collecting required information on carbon emission of Iron and steel, Alumunum, Copper and Magnesium process industries from the relevant journals published in the years 1990 to 2019 .

\section{Carbon emission from iron and steel industry}

The International Energy Outlook 2012 reported that the iron and steel industry is accounted for about 10 percent energy consumption of the total global manufacturing sector. ${ }^{13,14}$ This sector is also the second-largest industrial $\mathrm{CO}_{2 \mathrm{eq}}$ emitter due to its energy-intensive process. ${ }^{15}$ The sources of carbon emission from this sector are the fossil fuel-based power plants to produce the electricity for the steel industry; and as well as from the Iron production process. The coal and gas-fired power plants are the main sources of electricity and heat energy supply to Iron and steel process plants. ${ }^{16}$ When the traditional arc furnace has been used for iron processing, the recorded emission rate was found to be $0.4 \mathrm{tCO}_{2}$ eq. ( $\mathrm{t}$ crude steel) ${ }^{-1}$. In the case of using the integrated blast furnace, then the emission has appeared to be as high as $8 \mathrm{tCO}_{2}$ eq. ( $\mathrm{t}$ crude steel) $)^{-1}$. The recorded emission from a basic oxygen furnace would be up to $2.5 \mathrm{tCO}_{2}$ eq. $(\mathrm{t} \text { crude steel })^{-1}$. The global carbon emission data shows that the emission from Iron industries was $2.3 \mathrm{Gt}$ in 2016; and the projected contribution from this sector to global $\mathrm{CO}_{2 \mathrm{eq}}$ emissions would be about $4.5 \mathrm{Gt}$ in $2050 .{ }^{17}$ This information demonstrated that Iron and steel process industries are the potential carbon emission sources and need to be controlled its emission. In recent years, this industry has achieved a significant improvement in reducing carbon emission. It has been stated that due to the use of the advanced technology in metals process industries, the emission has reduced from $1.3 \mathrm{tCO}_{2}$ eq. ( $\mathrm{t}$ steel $)^{-1}$ to $0.2 \mathrm{tCO}_{2}$ eq. $(\mathrm{t} \text { steel })^{-1} \cdot{ }^{18,19}$ This industry would be able to reduce emissions by increasing energy efficiency, and thereby about 30 percent emission could be reduced. The use of hydropower for Iron and steel production, the industry would be able to reduce about 60 percent carbon emission, and which would be contributed to reducing emission from $1.3 \mathrm{tCO}_{2}$ t steel) to $0.45 \mathrm{tCO}_{2}$. (t steel $)^{-1} \cdot{ }^{20}$ The carbon capturing and storing (CCS) equipment has appeared to be a successful installation in the Iron and steel production process. It has been reported that CCS has contributed to reducing carbon emission from $1.3 \mathrm{tCO}_{2} .(\mathrm{t} \text { steel })^{-1}$ to about $0.15 \mathrm{tCO}_{\text {2eq. }}(\mathrm{t} \text { steel })^{-1} .^{18}$

\section{Carbon emission from aluminum industry}

The Intergovernmental Panel on Climate Change (IPCC) has marked Aluminum(AL) processing as a major GHG emissionintensive industry, and has emphasized to take required action for reducing emission from this industry from 50 to 85 percent by the year $2050 .{ }^{12,21}$ It was estimated that 65 percent of emissions predominately are occurring from electricity production that needs to operate the $\mathrm{AL}$ processing plant machinery. And other 35 percent GHG emits from AL production process. ${ }^{22}$ It was also found that the emission from AL processing plant is about $1.3 \mathrm{CO} 2 \mathrm{eq} .(\mathrm{t} \mathrm{AL})^{-1}$ when using coal for energy production; and it could be about $0.73 \mathrm{CO}_{2} \mathrm{eq}(\mathrm{t} \mathrm{AL})^{-1}$ when using gas as an energy source. ${ }^{23}$ The estimated contribution from $\mathrm{AL}$ production industry to total global GHG emissions was $0.45 \mathrm{GtCO}_{2} \mathrm{eq}$ in 2007 , which was approximately about 1.0 percent of the total global GHG emissions. ${ }^{12,23}$ Nowadays, a few options are available to reduce carbon emission from $\mathrm{Al}$ processing. The most popular way is to use the advanced technology in AL process to reduce energy consumption ${ }^{24}$ and as well as to reduce emission. ${ }^{12,23,25}$ The recycling waste $\mathrm{Al}$ in producing new products would be contributed to reducing a significant amount of carbon emission. ${ }^{12}$ Employing the CCS technology at the end of the AL process, the GHG emission would be reduced to a significant level. ${ }^{1}$

\section{Carbon emission from copper processing industries}

The emissions from copper melting industries, the GHG emissions are mostly sulfur dioxide, dust, nitrogen dioxide, carbon dioxide. ${ }^{26}$ Indeed, in both primary and secondary processes are associated with carbon emission. The fire refinement of draft copper process makes $181 \mathrm{~kg}$ of $\mathrm{CO}_{2}$ per ton of anode copper. Giurco and Petrie ${ }^{27}$ stated that to obtain $1.0 \mathrm{~kg}$ of $\mathrm{Cu}$ from an ore $(0.45 \% \mathrm{Cu})$ was estimated to be $7.0 \mathrm{~kg} \mathrm{CO}$ eq emission; he also found that emission rate from the $\mathrm{Cu}$ processing was dependent on the quality of the $\mathrm{Cu}$ Ore. Ekman et al. ${ }^{28}$ have stated from the Ecoinvent database that the emission from the $\mathrm{Cu}$ process reduced significantly from $6.62 \mathrm{~kg} \mathrm{CO}_{2}$ eq. $(\mathrm{kgCu})^{-1}$ to 2.80 kg CO${ }_{2}$ eq. $(\mathrm{kg} \mathrm{Cu})^{-1}$ due to the advancement of process technology. However,the highest emission was reported by Boesch et al. ${ }^{29}$ and the reported value was $1.9 \mathrm{~kg} \mathrm{CO}_{2}$-eq. $(\mathrm{kg} \mathrm{Cu})^{-1}$. Adopting the various recycling methodologies and process technology in this sector has contributed to reducing emissions. ${ }^{30}$ However, various estimates have shown that the total carbon emission starting from mining to product process is ranging from $1,474 \mathrm{~kg} \mathrm{CO}_{2 \mathrm{eq}} \cdot(\mathrm{kgCu})^{-1}$ to $1,600 \mathrm{kgCO}_{2}$ eq. $(\mathrm{kgCu})^{-1}$ of anode copper. ${ }^{31}$ Meanwhile, the problem of capturing the sulfur dioxide $\mathrm{SO}_{2}$ is being effectively solved at copper melting plants. For example, in the EU an average of $98.9 \%$ of sulfur has extracted from emission streams and used for the production of sulfuric acid. However, the issue of controlling and capturing the environmental harmful emission remains quite acute; though $\mathrm{Cu}$ production is still increasing to meet global demand. ${ }^{31}$

\section{Emission from magnesium production process}

In the magnesium process industry, a number of potential GHG emission sources have been reported. The major emission components are $\mathrm{CO}_{2}, \mathrm{HFC}$ gas and SF6 gas, which typically escape to the atmosphere during magnesium production from Orc. The amount and types of emission from that industry depend on the raw material quality being used for primary magnesium metal production and the types of the cover gas mixture have used in the casting and recycling foundries to prevent oxidation of molten magnesium. ${ }^{32}$ Both primary and secondary process; and casting operations are associated with GHG emission. Both primary and secondary processes; and casting operations are associated with GHG emission. The primary magnesium refers to metallic magnesium derived from mineral sources. The raw metals used for primary magnesium production are dolomite and magnesite. Processing of carbonate raw metals (magnesite and dolomite) also releases $\mathrm{CO}_{2}$. The $\mathrm{CO}_{2}$ is also released during calcination of carbonatebased ores such as dolomite/magnesite. ${ }^{11}$ The use of $\mathrm{CO}_{2}$ enriched gas 
as a cover gas for the magnesium process might cause a higher rate of emission with HFC gas and SF6 gas. It was estimated that for each kilogram of magnesium produced, theoretically, $3.62 \mathrm{kgCO}_{2 \mathrm{eq}}$ would release when using dolomite as a raw material. The emission would be $1.81 \mathrm{kgCO}_{2 \mathrm{eq}}$ for producing one kilogram of magnesium when to use magnesite as a raw material. ${ }^{5,11}$ The molten magnesium spontaneously burns in the presence of atmospheric oxygen and contributes to increasing emission. To reduce that emission requires a protection system to prevent spontaneous burning. It is suggested that the CCS might be used to capture GHG from the magnesium process in order to reduce global worming threats. ${ }^{33}$

\section{Conclusion}

This study conducted to contribute to achieve the global target to maintain carbon concentration of $445 \mathrm{ppm}$ in the air for keeping temperature increase well below $2^{\circ} \mathrm{C}$ compare to the pre-industrial development level. The common census that a huge amount of R\&D is required from engineering and science communities for developing low carbon technology for metals processing, and higher life cycle products from low carbon raw metals to reduce carbon emission. Carbon dioxide and methane is the major greenhouse gases (GHG). Presence of such gases in the Atmosphere of our planet, we facing greenhouse effect or climate change effects namely to increase the surface temperature, rising water level, and subsequently it would contribute to increasing biodiversity loss. Among the metals processing industries, Iron and Aluminum could be ranked as the highest GHG emitters. The second level is Copper, Zinc, Magnesium and Lead. It is suggested that by adopting green technology in the metal process such as introducing the CCS, the emission could be reduced up to 90 percent. The metal is the fundamental element that needs to build infrastructure for achieving a sustainable economy. Indeed, for the increasing of economic growth at a lower investment, metal process industries are being installed without adopting the carbon-capturing machinery. It also reported that a significant number of metal process industries have been operating without taking care of the emission factor which severely affecting to achieve a sustainable environment. ${ }^{20}$ This study concludes that the metals process industries shall grow for the supporting of economic growth but emission must control in order to achieve sustainability in the economy and environment.

\section{Acknowledgements}

Author would like to acknowledge the financial supports received from Ministry of Agriculture, State of Sarawak Malaysia under grant GL/F02/ORSSG/2016. Author is also pleased to offer special thanks to my beloved student, Eugene Jackson Joy and the academic staff of Engineering Faculty, Universiti Malaysia Sarawak.

\section{Conflicts of interest}

The authors declare no conflict of interest.

\section{Reference}

1. Shahidul. Engineering Role in Mitigating Global Climate Change Effects: Review in the Aspect of Carbon Emission from Fossil Fuel Based Power Plants and Manufacturing Industries. Reference Module in Materials Science and Materials Engineering. 2018:1-133.

2. Ben Abdallah K, Belloumi M, De Wolf D. Indicators for sustainable energy development: A multivariate cointegration and causality analysis from Tunisian road transport sector. Renew Sustain Energy Rev. 2013;25:34-43.
3. IPCC. Intergovernmental Panel on Climate Change. 2017.

4. IEA. World Energy Outlook 2016. Int Energy Agency Paris; 2016.

5. IPCC. Good practice guidance for land use, land use change and forestry. 2003.

6. Liu S, Hu Z, Wu S, et al. Methane and Nitrous Oxide Emissions Reduced Following Conversion of Rice Paddies to Inland Crab-Fish Aquaculture in Southeast China. Environ Sci Technol. 2016;50(2):633-642.

7. Wu S, Hu Z, Hu T, et al. Annual methane and nitrous oxide emissions from rice paddies and inland fish aquaculture wetlands in southeast China. Atmos Environ. 2018;175:135-144.

8. Yao Z, Zheng X, Liu C, et al. Stand age amplifies greenhouse gas and NO releases following conversion of rice paddy to tea plantations in subtropical China. Agric For Meteorol. 2018;248:386-396.

9. IPCC. IPCC Fifth Assessment Synthesis Report-Climate Change 2014 Synthesis Report. IPCC Fifth Assess Synth Report-Climate Chang 2014 Synth Rep. 2014.

10. Lee SJ, Ryu IS, Jeon SG, et al. Emission sources and mitigation of fluorinated Non-CO2greenhouse gas in registered CDM projects. Greenh Gases Sci Technol. 2017;7(4):589-601.

11. Bartos S, Marks J, Kantamaneni R, Laush C. Measured SF6 emissions from magnesium die casting operations. TMS Annual Meeting; 2003.

12. IAI. Global Aluminium Recycling. Int Alum Inst; 2009.

13. World Steel in Figures. Annu IISI Publ. 2007.

14. Li L, Lei Y, Pan D. Study of CO2 emissions in China's iron and steel industry based on economic input-output life cycle assessment. Nat Hazards. 2016;81(2):957-970.

15. Yu B, Li X, Qiao Y, et al. Low-carbon transition of iron and steel industry in China: Carbon intensity, economic growth and policy intervention. $J$ Environ Sci (China). 2015;28:137-147.

16. Wou AQ, Luo, XL, Quan C. Study on the definition of supply chain footprint and its influence factors in iron and steel Industry. J Environ Sci. 2015;3:1-5.

17. Allwood JM, Cullen JM, Milford RL. Options for achieving a $50 \%$ cut in industrial carbon emissions by 2050. Environ Sci Technol. 2010;44(6):1888-1894.

18. IEA. Tracking Industrial Energy Efficiency and $\mathrm{CO}_{2}$ Emissions.

19. Casillas C, Chan K, Fulton D, et al. Pilot testing of a membrane system for post-combustion $\mathrm{CO}_{2}$ capture. NETL $\mathrm{CO}_{2}$ capture. Pittsburgh, PA, USA. Technol Meet; 2015.

20. Technology Roadmaps: Carbon Capture and Storage in Industrial Applications. 2011.

21. Zeng M, Yang Y, Fan Q, et al. Coordination between clean energy generation and thermal power generation under the policy of "direct power-purchase for large users" in China. Utilities Policy. 2015;33:10-22.

22. IPCC. Climate Change 2007: Impacts, Adaptation and Vulnerability.

23. Zhang $\mathrm{W}$, $\mathrm{Li} \mathrm{H}$, Chen $\mathrm{B}$, et al. $\mathrm{CO}_{2}$ emission and mitigation potential estimations of China's primary aluminum industry. $J$ Clean Prod. 2015;103:863-872.

24. Kuo PC, Wu W. Design, optimization and energetic efficiency of producing hydrogen-rich gas from biomass steam gasification. Energies. 2015;8(1):94-110

25. Bjerge LM, Brevik P. $\mathrm{CO}_{2}$ capture in the cement industry, norcem $\mathrm{CO}_{2}$ capture project (Norway). Energy Procedia. 2014;63:6455-6463.

26. United Nations. What is the Kyoto Protocol? 2019. 
27. Giurco D, Petrie JG. Strategies for reducing the carbon footprint of copper: New technologies, more recycling or demand management? Miner Eng. 2007:842-853.

28. Ekman Nilsson A, Aragonés M, Torralvo F, et al. A Review of the Carbon Footprint of $\mathrm{Cu}$ and $\mathrm{Zn}$ Production from Primary and Secondary Sources. Minerals. 2017;7:168.

29. Boesch ME, Vadenbo C, Saner D, et al. An LCA model for waste incineration enhanced with new technologies for metal recovery and application to the case of Switzerland. Waste Manag. 2014;34(2):378-389.

30. Chaturvedi A, Strasser C, Eisinger F, et al. The carbon footprint of e-waste recycling - Indian scenarios. In: Electronics Goes Green 2012+, ECG 2012 - Joint International Conference and Exhibition, Proceedings. 2012 .
31. Chesnokov Y, Lisienko V, Holod S, et al. Estimation of $\mathrm{CO}_{2}$-Equivalent Emission under the Copper Fire Refining Process. IOP Conf Ser Earth Environ Sci. 2017;72:12013.

32. Hort N, Wiese B, Dieringa H, Kainer K. Protecting molten magnesium and its alloys. La Metall Ital. 2016;108:105-108.

33. Anderson S, Newell R. Prospects for Carbon Capture and Storage Technologies. Annu Rev Environ Resour. 2004;29(1):109-142. 